\title{
Cosmopolitismo copyleft. Tumbona Ediciones, autonomía y localidad
}

Uno de los problemas centrales en el estudio de la literatura contemporánea radica en su elusiva materialidad como institución y práctica. En el caso latinoamericano, el panorama de publicación, circulación y consumo de la literatura ha sido objeto de transformaciones infraestructurales profundas, cuyos efectos tanto en la idea de la literatura como en las estéticas y políticas que intervienen en su figuración son siempre estudiados en una suerte de time-lag, una aproximación siempre tardía ante la dificultad de acercarse críticamente a la aceleración material de la cultura. A pesar de haber perdido y continuar perdiendo privilegios epistemológicos y críticos en vista tanto de la explosión multimediática de la era del internet como de las metodologías y aproximaciones transdisciplinares de los estudios culturales, la literatura como disciplina y la obra literaria como objeto siguen manteniendo un valor aurático como espacios de resistencia a las hegemonías globalizantes, los flujos del mercado y el arrasamiento necropolítico que han caracterizado la experiencia neoliberal de la región. Si hemos de responder la pregunta respecto al rol de las literaturas locales como resistencia a la hegemonización de la llamada "literatura mundial", la atención a la materialidad infraestructural de la producción literaria, y la relación tensional y paradójica de la forma literaria respecto a esa materialidad requieren ser atendidas.

Este artículo reflexiona sobre este problema a partir del proyecto Tumbona Ediciones, una editorial independiente fundada en principios de autonomía, colectivismo y copyleft en México en 2005 y dirigida por los escritores Luigi Amara y Vivian Abenshushan. Los fundadores describen así el proyecto:

Bajo el lema "El derecho universal a la pereza", Tumbona Ediciones reúne a un grupo de creadores artísticos que desde el 2005 propone un tipo de resistencia creativa frente al progresivo empobrecimiento cultural del país. Nuestra intención es dar hospitalidad y circulación a los géneros más desatendidos por los grandes grupos (ensayo, aforismo, cuento), así como a títulos y apuestas poco frecuentes en nuestro panorama editorial (libros visuales de pequeño formato, flipbooks o cine de dedo). Libros con espíritu heterodoxo e irreverente, libros con vitalidad estética y riesgo intelectual, libros impuros que puedan ir de un lado a otro de las ramificaciones artísticas, esos son los libros que publicamos. (“Sobre la Tumbona” s.f.)

Ignacio M. Sánchez Prado, Washington University in St. Louis 
En esta breve descripción, emerge una terminología que permite entender estrategias de construcción de una "literatura mundial" desde abajo, a contrapelo de la literatura mundial construida desde arriba a través de circuitos hegemónicos de circulación transnacional. Tumbona se erige a sí misma como "resistencia creativa frente al empobrecimiento cultural del país”, sugiriendo una lectura de las condiciones hegemónicas de producción literaria como una gradual erosión de la cultura misma. Ante la “desatención” de los grandes grupos ante géneros nucleares de la tradición literaria mundial que no participan de manera obvia en el mercado (como el aforismo o el ensayo), proponen la idea de la "hospitalidad" y la "circulación” como contraparte. Si bien la idea parece simple (publicar aquello que no se publica en el circuito comercial), el concepto de "hospitalidad" tiene en el contexto de la época actual una serie compleja de implicaciones en la tensión entre lo nacional y lo mundial. En el contexto de los debates sobre inmigración, Jacques Derrida discute la distinción y tensión entre la "hospitalidad incondicional" y "los derechos y deberes que son las condiciones de la hospitalidad”. Según Derrida, la migración (y yo diría aquí la totalidad de circulación de bienes, cuerpos y símbolos en la era contemporánea) se funda en la tensión entre el deseo incondicional y la ley absoluta de la hospitalidad, el deseo de recibir lo forastero en casa, y la ética y política de la hospitalidad, siempre condicional (Doufourmantelle y Derrida 147). Para no caer en una digresión teórica, basta para mis propósitos comprender que el tema que interesa a Derrida es el hecho de que ambas formas de la hospitalidad no se contradicen, sino que "they appeal to each other, in a disconcerting way” (Derrida, "The Principle” 6): por un lado existe una ética en la cual se abren las puertas de un hogar, y por otro existen comunidades lingüísticas, familiares o nacionales que no se suspenden al ejercer la hospitalidad. Por tanto, concluye Derrida, debemos pensar en una "double law of hospitality: to calculate the risks, yes, but without closing the door on the incalculable, that is, on the future and the foreigner" (6).

Si leemos el manifiesto de Tumbona desde esta acepción de hospitalidad, podemos plantear la idea de que el cosmopolitismo y la literatura tanto nacional como mundial a la que apela un proyecto editorial independiente funciona bajo los condicionamientos éticos y culturales de una lógica de la circulación que simultáneamente abre de manera incondicional las puertas de una tradición a una serie de libros y bienes culturales mundiales, a la vez que establece reglas y condicionamientos que permiten definir una ciudadanía cultural propia. Como en Derrida, su hospitalidad se basa en la pregunta sobre la ética y la política de la cultura de la globalización en su encuentro problemático tanto con las culturas nacionales (materializadas en regímenes legislativos y simbólicos de restricción de la circulación) como con la cultura global capitalista (que fomenta una libre circulación de bienes erosionando formas de vida y de pensamiento). En Derrida, tanto 
la hospitalidad como el cosmopolitismo se fundan en la tensión entre una responsabilidad infinita hacia el Otro y el pragmatismo que conlleva dicha responsabilidad en el espacio de lo particular (Derrida, Cosmopolites). Así, proyectos editoriales como Tumbona se basan en el desplazamiento de los dos términos hacia espacios distintos a los promulgados por la libre circulación del capital literario (la literatura que Rebecca Walkowitz llama "born translated” y que está escrita para la circulación sin fricciones a través de espacios culturales y lingüísticos. Por un lado, en vez de apelar a una universalidad pre-establecida por los principios de circulación de la literatura comercial, Tumbona opta por un principio de hospitalidad hacia los géneros "impuros", basado en un "derecho universal a la pereza" que constituye un marco simbólico-legal alterno a las nociones de industria cultural y trabajo cultural que subyacen a las obras literarias que participan de lo que Sarah Brouillette, a partir de una lectura crítica del sociólogo Richard Florida, llama la "economía creativa”. A la vez, al aplicar pragmáticamente esta hospitalidad a su catálogo, Tumbona establece una serie de limitantes y criterios que efectivamente ponen reglas y condicionantes a la literatura que publican, algo necesario para definir su cosmopolitismo opuesto al mercado. Así, términos como "heterodoxo" e "irreverente" reemplazan las condicionantes del mercado ("ligero", "legible”, etc.) como infraestructura estético-legal de la hospitalidad del proyecto. Estructuralmente hablando es un cosmopolitismo que sigue las mismas reglas, discutidas por Derrida, de cualquier otro cosmopolitismo involucrado en la tensión entre lo nacional y lo global, sea este migratorio, económico o simbólico. Pero se trata de un cosmopolitismo, en este caso editorial, que resiste las leyes de circulación (como el "nacer traducido" de Walkowitz o el circuito transnacional de agentes y mediadores) y de restricción (las leyes de copyright, las restricciones del "literatura nacional") del cosmopolitismo comercial a partir del establecimiento de leyes alternas: circulación en libro e internet, establecimiento de un movimiento copyleft, introducción al mercado de géneros no vendibles, etc.

La legibilidad del proyecto de Tumbona ediciones emerge en contraste al cambio de coordenadas de la infraestructura editorial latinoamericana que comienza en los años ochenta y que continúa hasta nuestros días. La cuestión de los realineamientos del mercado es compleja y ha sido discutida en varios textos relevantes (sobre todo Ruisánchez y Guerrero para el tema al que dedico estas páginas), así que no me expandiré en demasía sobre el tema Tumbona nace a contrapelo de fenómenos que han redefinido la publicación en habla hispana. La primera es la fuerte consolidación corporativa de la publicación en la región, que incluye la gradual emergencia de los dos titanes que controlan un porcentaje alto de la publicación de libros: el Grupo Planeta y, sobre todo, Penguin Random House Mondadori, que incluso ha absorbido a Alfaguara, el gigante mayor de la publicación literaria en español de los noventa. La segunda tiene que ver con 
editoriales que, en resistencia a esa consolidación corporativa, han en distintos periodos tratado de posicionarse como editoriales de concepto y hacer competencia a nivel nacional o transnacional a los dos corporativos: estas editoriales incluyen a Anagrama y Periférica en España, Eterna Cadencia y Mardulce en Argentina, LOM en Chile, Era, Sexto Piso y Almadía en México, por mencionar a algunas. Estos dos factores tienen como efecto paradójico una renacionalización de la literatura ya que las primeras suelen segmentar su publicación por países, transnacionalizando solamente autores específicos, mientras que las segundas (sobre todo las latinoamericanas) circulan poco fuera de su ámbito nacional o (en el caso de Anagrama por ejemplo) mantienen filiales locales que diferencian precios de los autores nacionales respecto al resto del catálogo. Como observa atinadamente Gustavo Guerrero,

El recentramiento del negocio en torno a la producción local no sólo trae como consecuencia una acentuación del proceso de balcanización y aislamiento tradicional de las distintas literaturas nacionales sino que acaba convirtiendo a lo nacional en una especie de efecto del mercado cuyo contenido y alcance suscita severas críticas y reservas, sobre todo en lo que toca al rediseño del campo por parte de agentes foráneos y en lo que respecta a la revisión de las jerarquías establecidas en función del nivel de ventas. (105)

Asimismo, continúa Guerrero, este proceso viene acompañado de "una puesta en escena simultánea de su crisis, pues, a todo lo largo de la década, el mercado se segmenta nichos y se convierte en una caja de resonancia social de las diferencias, en una vitrina para la afirmación del multiculturalismo" (106). A esto cabría agregar también que estas cajas de resonancia (una nacional y una serie de cajas identitarias hacia dentro de ellas) no solo han vaciado de sentido la idea de literatura latinoamericana a través de las restricciones en la circulación (algo sobre lo que ha reflexionado de manera radical Jorge Volpi, El insomnio) sino también construyen una literatura mundial cuyos parámetros de canonización están completamente fuera de la práctica literaria latinoamericana, funcionalizados a contratos de edición negociados en mercados como Frankfurt y a la previa canonización en el francés o el inglés. Hay que recordar, por ejemplo, que autores como Sergio Pitol lograron crear un canon de literatura mundial distinto al producido por los circuitos hegemónicos transnacionales precisamente porque la relativa autonomía que gozó la edición en español entre los años sesenta y ochenta, anterior a la consolidación corporativa, permitía a traductores, creadores y críticos publicar constelaciones de autores mundiales distintas a las de otras lenguas ${ }^{1}$. Siguiendo el concepto de hospitalidad, es posible decir que este panorama editorial es inhóspito. Por un lado, restringe significativamente

1 Sobre esto, véase Sánchez Prado, capítulo 1. 
tanto el género de las obras literarias que circulan de tradición en tradición como sus orígenes lingüísticos y estéticos, procesando todo por un sistema comercial que en general es exógeno a las prácticas literarias de base en los países latinoamericanos. A su vez, los sistemas literarios nacionales se vuelven más cerrados de lo que eran antes, pero además son construidos por políticas de edición y de mercado de corporaciones localizadas en espacios geográficos hegemónicos (España, Estados Unidos, etc.) impidiendo a las literatura locales el establecimiento de las reglas y principios de hospitalidad necesarias para la creación y preservación de identidades estéticas e ideológicas de campos literarios específicos.

Tumbona pertenece a un tercer ámbito de editoriales que, ante este desafío, buscan construir procesos de literatura mundial y nacional a partir de desafiar no solo a la hegemonía en las estructuras de publicación y distribución que los corporativos fomentan, sino también al privilegio que formas tradicionales de la escritura -sobre todo la novela, el cuento y las narrativas de no-ficción como la crónica y la memoria- tienen en la canonización literaria del mundo hispanohablante. Conviene recordar que la centralidad de la novela en América Latina es un fenómeno reciente, atado a la inserción misma de América Latina en el mercado transnacional del libro en la era del Boom. La respuesta dada por Tumbona emerge por un cambio tecnológico central a la producción literaria latinoamericana y global. En un ensayo clásico sobre el Boom, Jean Franco propone una historia de la narrativa latinoamericana basada en registrar los tipos de autoría relacionados con avances tecnológicos en el arte de la narración. Así, Franco distingue al "narrador" (en el sentido benjaminiano del término) como un resabio de las tradiciones orales y al autor como la figura que emerge a partir del establecimiento, y ampliación, de las tecnologías de la imprenta (51-53). La novela latinoamericana del nuevo siglo establecería así un modelo distinto al autor europeo, cuya característica es la utilización de la novela como el género del individuo en la sociedad, mientras que el modelo predominante en América Latina sería el autor como "fundador" desde los márgenes (157-159). La entrada al ámbito de la literatura de los medios masivos y electrónicos permite la emergencia del autor "superstar" que asume los principios de la cultura de masas y contribuye a la erosión de ciertas formas tradicioales de la novela ante la primacía de la imagen del autor mismo (166-167). En cierto sentido, la literatura de mercado de hoy en día no es algo nuevo, sino una aceleración y expansión del modelo del superstar: autores como Roberto Bolaño, Orhan Pamuk o Elena Ferrante, pese incluso al hecho de que sus obras ponen elementos de sus precursores en entredicho, son consumidos por el mercado de maneras muy similares a las que fueron desarrolladas alrededor de figuras como Gabriel García Márquez, 
Umberto Eco o Milán Kundera décadas atrás ${ }^{2}$. Las aperturas que se pueden ver en el mercado tienen que ver con las descentralizaciones que cambios tecnológicos recientes (como el blog, las redes sociales y el libro electrónico) han tenido no tanto en la desestabilización del sistema hegenómico (que sigue operando sin novedad) sino en la proliferación de posibilidades alternas a dicho sistema.

Tumbona puede ser ubicada en el cuadrante de lo que Craig Epplin llama, para el caso argentino, "late book culture", un intraducible que busca registrar la existencia de una cultura que no es post-libresca del todo, pero que navega las incertidumbres del futuro del libro como soporte material único de la escritura literaria. El proyecto de Tumbona emerge en un punto en el cual la escritura literaria latinoamericana ha mudado, como explica Epplin, de ecosistemas. En México, esto comenzaba a verse de manera decisiva en la década pasada, ante la emergencia del blog como precursor o complementador de proyectos novelísticos (cabe recordar, por ejemplo, El jardín devastado, de Jorge Volpi (2008), publicado originalmente en blog, o el proyecto de Cristina Rivera Garza, cuyo blog No hay tal lugar dio partida a una constelación de libros interconectados, incluyendo la novela La muerte me da (2008)). Si bien las cartoneras en México no tuvieron, debido al peso institucional del Estado, la relevancia que adquirieron en Argentina, existen ideas comunitarias del libro que operan desde principios parecidos, como la editorial Sur+ de Oaxaca, que se define a sí misma como "editorial colectiva independiente" o Mantarraya Ediciones, un proyecto editorial atado a Hosteria La Bota -restaurante y centro cultural de Antonio Calera Grobet- y La Chula Foro Móvil, una combi de los años setenta que lleva eventos culturales a comunidades marginadas de la Ciudad de México. Lo que se observa en el caso mexicano, y establece diferencias importantes respecto al caso argentino estudiado por Epplin, es que el problema del soporte libro es parte de una constelación mayor de intervenciones. Por un lado, el blog, las redes sociales y las nuevas formas de comunitarismo literario que han propagado autores como Rivera Garza o Alberto Chimal hablan de una noción de la escritura literaria que excede al libro. Pero, en el contexto de una literatura altamente institucionalizada en un sistema de premios, becas y subsidios del Estado en proporciones inexistentes en cualquier otro país latinoamericano, Sur+, Mantarraya y Tumbona piensan la localía y la resistencia a la hegemonía cultural desde la intervención de la infraestructura misma. Así, Mantarraya constituye una edición de libros alrededor de un proyecto gastronómico y un espacio de difusión cultural que dan vuelta y que complementan la materialidad cultural

2 Sobre la forma en que Bolaño repite patrones de García Márquez en su circulación de mercado, véase Pollack. 
de Estado. Tumbona, por su parte, apela a la intervención estética en dos formas: el rechazo del copyright y el valor económico del libro y la consecuente promoción de formas de escritura que solo son pensables desde dicho rechazo.

El catálogo de Tumbona es demasiado complejo y amplio para dar cuenta de él de manera exhaustiva en un estudio como este, así que me enfocaré solamente en libros particulares para plantear algunas ideas centrales cuáles son los espacios de intervención de la editorial en la tensión entre literatura mundial y literatura nacional que subraya la hospitalidad de su proyecto. Destaca, por ejemplo, el volumen colectivo Contra el copyright (Stallman), una reflexión en cinco ensayos que recorre la idea del derecho a la lectura, el problema del copyright, la idea del copyleft y la cuestión del futuro digital. El libro aparece en la serie Versus, un conjunto de breves libros -a veces de un autor, a veces de un conjunto de autores- que entran en polémica contra principios y mecanismos de la era contemporánea en defensa de la filosofía general de la pereza y la hospitalidad de la editorial (hay por ejemplo, un volumen contra la "vida activa” (Lemus) o el conocido ensayo de Lina Meruane contra los hijos). En el volumen contra el copyright se puede ver ya la idea de una literatura mundial que la editorial recibe a través de su hospitalidad, y que se basa en la lectura de una constelación de prácticas y practicantes de la literatura que ponen en entredicho la idea misma de literatura de mercado. Los dos textos sobre copyright y copyleft, por ejemplo, provienen del colectivo Wu Ming, un grupo de autores italianos activo entre el año 2000 y el 2011 que, en el contexto del régimen de Berlusconi, publicaron una serie de novelas bajo licencia Creative Commons. El texto del derecho a la lectura fue escrito por Richard Stallman, el fundador de la idea del software libre y el pionero del concepto mismo de copyleft y de las licencias públicas generales. Un texto sobre el derecho al plagio fue escrito por César Rendueles, un pensador español conocido por su obra sobre los cambios políticos de la era digital, mientras que el del futuro digital es de Kembrew McLeod, un estudioso de la comunicación cuyo reconocimiento viene de su patente de la idea de "libertad de expresión" y su demanda contra la compañía AT\&T por su uso promocional del término, para poner en evidencia los absurdos de la ley de propiedad intelectual.

Destaca de este libro el carácter de manifiesto que la compilación tiene. Uno de los diagnósticos centrales del proyecto de Tumbona radica en "la transición de la censura del Estado a la no menos efectiva del mercado", en la cual "los libros se volvieron mercancías perecederas, que debían venderse en tiempo record" (Loy y Locane 74). En esto, los editores de Tumbona coinciden con diversos diagnósticos de fines de los noventa e inicios del siglo XXI, que veían una suerte de proliferación de la violencia contra la literatura a partir de lo que 
uno podría llamar una nueva microfísica donde el poder centralizado de la censura del Estado comenzaba, particularmente en las sociedades occidentales, a difuminarse en mecanismos de mercado. Esto fue una denuncia que venía tanto de editores como André Schiffrin, cuyo The Business of Books denunciaba la manera en que los conglomerados corporativos reemplazaban a los editores del siglo XX, o críticos como Christian Salmon, quien diagnosticaba en Tumba de la ficción que "las formas tradicionales de censura jurídica e institucional están desapareciendo sustituidas por formas nuevas”, cuyo fin es la instalación del "reino de lo homogéneo y su fobia por el arte y la ficción” (15).

Vivian Abenshushan, una de las fundadoras y editoras de Tumbona, argumenta que el copyright es uno de los mecanismos que permite dicha censura. En un texto sobre el tema, Abenshushan argumenta que la "tiranía del copyright sofoca la cultura" y pone como ejemplo un libro de arte que deja recuadros en blanco porque "no consiguieron los derechos de reproducción de algunas imágenes y el resto resultaba impagable" (Escritos 267). Ante esto, el copyleft es una estrategia que permite la apropiación y recirculación de los objetos culturales, contrastando "la economía del máximo beneficio frente a la economía del regalo” (275-276). Podríamos decir entonces que Tumbona se funda en un cosmopolitismo copyleft, donde la globalización y la mundialización de las culturas no se fundan en la libre circulación de mercancías en el ámbito de lo económico, pero fuertemente controladas por entidades comerciales empoderadas por las leyes del copyright. Eso es lo que permite, por ejemplo, que editoriales como Planeta o Penguin Random House ejerzan un derecho absoluto de publicación sobre un libro de literatura latinoamericana en todos los idiomas, a la vez que decide solo publicarlo en el país de origen de la autora y, de hecho, restringir completamente la producción en otros lugares. Asimismo, Abenshushan arguye, esto no impide la apropiación que la cultura corporativa hace de las culturas marginales. Pone como ejemplo la canción "Waka Waka” de Shakira y Wyclef Jean para hablar de un "plagio imperial" que roba a culturas periféricas para el beneficio comercial de culturas dominantes (Escritos 270). En el contexto de la idea de literatura mundial, creo que esta aseveración, junto al catálogo de Tumbona, puede leerse como un argumento respecto a una forma de ejercerla de manera alternativa a la planteada por los corporativos editoriales. Los críticos de la relación entre cultura poscolonial y literatura mundial (Huggan; Brouillette, Postcolonial) han demostrado con suficiencia que la mera representación de lo marginal puede ser perfectamente compatible con los procesos de hegemonización y homogeneización de la literatura mundial corporativa. Lo que argumenta Abenshushan en sus escritos, y Tumbona en general como proyecto, es que no puede resistirse significativamente al mercado si uno sigue operando dentro de sus términos o si uno simplemente atiende al contenido de las publicaciones. El 
cosmopolitismo copyleft debe comprenderse así como una intervención en la literatura mundial a nivel de infraestructura, cuestionando la materialidad que permite la hegemonización, desde los regímenes jurídicos de propiedad intelectual hasta los calendarios de publicación basados en la maximización del lucro.

Tumbona no es una editorial de tesis, pero sí mantiene un sentido claro del canon, sobre todo de un canon interesado en repensar escrituras que resisten la propiedad, la economización y el trabajo. Con base a esto articula los dos términos de la dialéctica de la hospitalidad: un espacio para dar la bienvenida a escrituras nómadas que no entrarían de manera clara a la tradición mexicana, y una tradición mexicana cuya relación material con el mundo y la literatura sale de los parámetros de los cosmopolitismos hegemónicos tanto del mercado como del campo de producción cultural del siglo XX. Estos archivos nos permiten ver, primero, cómo la intervención en la idea misma del texto canonizable plantea la posibilidad de un "cosmopolitismo copyleft”, que, fuera de la mercancía y objeto del libro y el privilegio capitalista a la novela, permiten recuperar una tradición literaria basada en repertorios, prácticas y formas performativas de la literatura que carecen de fijación en el ámbito de la mercancía. Por otro, es posible ver la forma en la cual se piensa la idea del escritor contemporáneo mexicano y latinoamericano en correlación a formas de ser escritor mundial que no pasan por la validación de las estructuras hegemónicas del mercado. Esto es observable en los dos "Archivos" que, en tres volúmenes cada uno, apuestan a una recuperación precisa del pasado.

El primero de estos archivos es "Archivo Fluxus" (Kaprow; Higgins; Friedman, Smith y Sawchyn), en el cual Tumbona recupera en tres volúmenes textos, imágenes e intervenciones del colectivo artístico neo-dadaísta Fluxus, al que pertenecieron entre otros Allen Kaprow, Joseph Beuys y Yoko Ono, y que buscaron en sus momentos más radicales la construcción de formas de arte que rompieran no solo barreras disciplinares sino también espacios utópicos de ruptura de la relación jerárquica entre creador y espectador. Los tres libros del Archivo Fluxus operan bajo la premisa de un cosmopolitismo literario que deja de estar anclado, como es el caso de mucha de la literatura mundial, en las tradiciones de la novela moderna y del modernismo global, y más bien apela al gesto neovanguardista de cuestionamiento de la institución arte y la institución literatura para reflexionar sobre el posicionamiento mismo de la literatura y el arte contemporáneos en la Latinoamérica contemporánea. Abenshushan lo plantea en estos términos en uno de sus ensayos sobre el Archivo:

Incoercible, antisolemne, abierta a la experimentación, animada por la colaboración y las prácticas colectivas, donde las disciplinas convivieron en promiscuidad fecundante para crear lenguajes inéditos como el happening o el videoarte, la actividad contracultural de 
Fluxus fue a su modo una cristalización del espíritu de la época. "Un modo de vida impregnado de una soberbia libertad de pensar, de expresar y de elegir”, escribió Robert Filliou. Más una zona temporalmente autónoma que una prefiguración del conceptualismo global, como han interpretado algunas versiones momificadoras. Un continente del absurdo (y del sentido del humor y la subversión y la imaginación radical). Un lugar sin lugar, donde Fourier habría vivido plácidamente. ("Fluxus" s.p.)

Esta descripción va directamente al tipo de genealogía que busca construir Tumbona: ante una cultura global definida por el capital y la propiedad intelectual, Tumbona recupera en Fluxus la colaboración y la colectividad, ante el disciplinamiento de las academias y los géneros artísticos, Fluxus representa la promiscuidad estética y la transdisciplinareidad, ante el conceptualismo global y el arte contemporáneo, un performance continuo y utópico de la imaginación radical.

El segundo proyecto es el "Archivo Ulises Carrión”, editado por Juan J. Agius y Heriberto Yépez, que colecciona en tres libros un conjunto de escritos, textos visuales y misceláneas del escritor y artista conceptual mexicano (Carrión, El arte correo; Lilia Prado; El arte nuevo). Carrión ha adquirido recientemente una centralidad considerable, a partir sobre todo de la exhibición de sus obras que, bajo el título de “Querido lector, no lea”, tuvo lugar en el Museo Reina Sofía en Madrid y el Museo Jumex en la Ciudad de México (Schraenen). Al igual que Fluxus, Carrión pertenece a un estilo heterodoxo de escritor que pone al centro de la creación literaria la producción de textos efímeros que impiden su fijación en el espacio de la mercancía o del libro. Carrión opera programáticamente a partir de la disociación entre texto y libro ("Un escritor", dice Carrión en uno de sus manifiestos, "contrariamente a la opinión popular no escribe libros / Un escritor escribe textos" (El arte nuevo 37)). Así, Carrión rechaza una forma del "arte viejo" en el cual el escritor produce un texto y un sistema económico ("los lacayos, los artesanos, los obreros, los otros" (39) producen el objeto libro. A cambio de esto, Carrión propone un "arte nuevo" en el que "el escritor asume la responsabilidad del proceso entero" (39)). Las razones por las cuales el "arte nuevo" de Carrión es el núcleo que permite ver la naturaleza de un proyecto como Tumbona y el replanteamiento de la literatura mundial que lo subyace son evidentes. Primero, es importante señalar que Carrión constituye un modelo único de escritor transnacional que, al disociarse del libro y al operar desde sitios como Ámsterdam, permite pensar una literatura mundial definida por prácticas materiales y para el mercado. Segundo, el arte nuevo de Carrión adelanta formas en las cuales proyectos como Tumbona y escritores como Heriberto Yépez trabajan alrededor de las instituciones literarias para controlar el proceso de producción literaria. La teorización de Carrión antecede la forma en que el blog, la 
publicación en Creative Commons (que Tumbona usa para liberar las versiones electrónicas de algunos de los libros) y el cuestionamiento de la plusvalía cultural operan en el siglo XXI.

\section{Bibliografía}

Abenshushan, Vivian. “Fluxus. Hágalo usted mismo”. Nexos en línea, 14 de junio 2016. https://cultura.nexos.com.mx/?p=10630, consultado 15 de agosto 2018.

---. Escritos para desocupados. Surplus, 2013.

Brouillette, Sarah. Literature and the Creative Economy. Stanford University Press, 2014.

---. Postcolonial Writers in the Global Literary Marketplace. Palgrave Macmillan, 2007.

Carrión, Ulises. El arte nuevo de hacer libros. Archivo Carrión 1. Segunda Edición. Eds. Juan J. Agius y Heriberto Yépez. Tumbona, 2016.

---. Lilia Prado superestrella y otros chismes. Archivo Carrión 3. Eds. Juan J. Agius y Heriberto Yépez. Tumbona, 2014.

---. El arte correo y el gran monstruo. Archivo Carrión 2. Eds. Juan J. Agius y Heriberto Yépez. Tumbona, 2013.

Derrida, Jacques. “The Principle of Hospitality”. Parallax, 11.1, 2005, pp. 6-9.

---. Cosmopolites de tous les pays, encore un effort! Galilée, 1997.

Dufourmantelle, Anne y Derrida, Jacques. Of Hospitality. Anne Duforumantelle invites Jacques Derrida to respond. Trad. Rachel Bowlby. Stanford University Press, 2000.

Epplin, Craig. Late Book Culture in Argentina. Bloomsbury, 2014.

Franco, Jean. Critical Passions. Selected Essays. Duke University Press, 1999.

Friedman, Ken, Owen Smith y Lauren Sawchyn. Cuaderno de ejercicios. Eventos, acciones y performances. Tumbona, 2016.

Guerrero, Gustavo. Paisajes en movimiento. Literatura y cambio cultural entre dos siglos. Eterna Cadencia, 2018.

Higgins, Dick. [Breve] autobiografía de la originalidad. Tumbona, 2015.

Kaprow, Allen. Ensayos sin títulos y otros happenings. Tumbona, 2013.

Lemus, Rafael. Contra la vida activa. Tumbona, 2008.

Loy, Benjamin y Jorge Locane. “'La única manera de sobrevivir para nosotros ha sido apelar a la imaginación'. Una conversación con la cooperativa Tumbona Ediciones”. alba. lateinamerika lesen, 7, 2015, pp. 75-78.

Meruane, Lina. Contra los hijos. Tumbona, 2014.

Pollack, Sarah. “Latin America Translated (Again). Roberto Bolaño's The Savage Detectives in the United States". Comparative Literature, 61.3, 2009, pp. 346-365.

Rivera Garza, Cristina. La muerte me da. Tusquets, 2008.

Ruisánchez, José Ramón. Libro mercado. Literatura y neoliberalismo. Universidad Iberoamericana, 2015.

Salmon, Christian. Tumba de la ficción. Trad. Thomas Kauf. Anagrama, 2001.

Sánchez Prado, Ignacio M. Strategic Occidentalism. On Mexican Fiction, the Neoliberal Book Market and the Question of World Literature. Northwestern University Press, 2018.

Schiffrin, André. The Business of Books. How International Conglomerates Took Over Publishing and Changed the Way We Read. Verso, 2001. 
Schraenen, Guy. Querido lector no lea: Ulises Carrión. Museo Nacional Centro de Arte Reina Sofía, 2016.

"Sobre la Tumbona" (sin fecha). www.tumbonaediciones.com/sitio/sobre-la-tumbona, consultado 13 de agosto 2018.

Stallman, Richard, Wu Ming, César Rendueles y Kembrew McLeod. Contra el copyright. Tumbona, 2008.

Volpi, Jorge. El insomnio de Bolívar. Cuatro consideraciones intempestivas sobre América Latina en el siglo XXI. Debate, 2009.

---. El jardín devastado. Alfaguara, 2008.

Walkowitz, Rebecca L. Born Translated. The Contemporary Novel in the Age of World Literature. Columbia University Press, 2017. 